OPEN ACCESS

Edited by:

Burkhard Kleuser,

University of Potsdam, Germany

Reviewed by:

Christoph Wülfing,

University of Bristol, United Kingdom

Sid P. Kerkar

Boehringer Ingelheim, United States

${ }^{*}$ Correspondence:

Niklas Beyersdor

niklas.beyersdorf@

vim.uni-wuerzburg.de

Specialty section

This article was submitted to

$T$ Cell Biology

a section of the journal

Frontiers in Immunology

Received: 31 May 2019

Accepted: 19 September 2019

Published: 11 October 2019

Citation:

Hollmann C, Wiese T, Dennstädt F

Fink J, Schneider-Schaulies $J$ and

Beyersdorf N (2019) Translational

Approaches Targeting Ceramide

Generation From Sphingomyelin in T

Cells to Modulate Immunity in

Humans. Front. Immunol. 10:2363.

doi: 10.3389/fimmu.2019.02363

\section{Translational Approaches Targeting Ceramide Generation From Sphingomyelin in T Cells to Modulate Immunity in Humans}

\author{
Claudia Hollmann ${ }^{1}$, Teresa Wiese ${ }^{1}$, Fabio Dennstädt ${ }^{1}$, Julian Fink ${ }^{2}$, \\ Jürgen Schneider-Schaulies ${ }^{1}$ and Niklas Beyersdorf ${ }^{\text {t* }}$ \\ ${ }^{1}$ Institute for Virology and Immunobiology, University of Würzburg, Würzburg, Germany, ${ }^{2}$ Institute of Organic Chemistry, \\ University of Würzburg, Würzburg, Germany
}

In T cells, as in all other cells of the body, sphingolipids form important structural components of membranes. Due to metabolic modifications, sphingolipids additionally play an active part in the signaling of cell surface receptors of $T$ cells like the $T$ cell receptor or the co-stimulatory molecule CD28. Moreover, the sphingolipid composition of their membranes crucially affects the integrity and function of subcellular compartments such as the lysosome. Previously, studying sphingolipid metabolism has been severely hampered by the limited number of analytical methods/model systems available. Besides well-established high resolution mass spectrometry new tools are now available like novel minimally modified sphingolipid subspecies for click chemistry as well as recently generated mouse mutants with deficiencies/overexpression of sphingolipid-modifying enzymes. Making use of these tools we and others discovered that the sphingolipid sphingomyelin is metabolized to ceramide to different degrees in distinct $T$ cell subpopulations of mice and humans. This knowledge has already been translated into novel immunomodulatory approaches in mice and will in the future hopefully also be applicable to humans. In this paper we are, thus, summarizing the most recent findings on the impact of sphingolipid metabolism on T cell activation, differentiation, and effector functions. Moreover, we are discussing the therapeutic concepts arising from these insights and drugs or drug candidates which are already in clinical use or could be developed for clinical use in patients with diseases as distant as major depression and chronic viral infection.

Keywords: sphingolipids, $\mathrm{CD}_{4}^{+} \mathrm{T}$ cells, regulatory $\mathrm{T}$ cells (Treg), $\mathrm{CD} 8^{+} \mathrm{T}$ cells, anti-depressant drug

\section{INTRODUCTION}

Subsets of $\mathrm{T}$ cells are major contributors to adaptive immunity. In particular, $\mathrm{CD} 4^{+} \mathrm{T}$ helper and $\mathrm{CD}^{+} \mathrm{T}$ cells either crucially orchestrate adaptive immune response or are direct mediators of e.g., anti-viral immunity, respectively. In order to be able to fulfill these tasks $\mathrm{T}$ cell precursors have to run through a stringent process of positive and negative selection within the thymus [reviewed in (1)]. However, it has been clear for decades that the process of negative selection does not completely eliminate maturing autoreactive $\mathrm{T}$ cells. This means that also in healthy human individuals autoreactive $\mathrm{T}$ cells can be detected (2-5) which, however, only cause autoimmune 
diseases like multiple sclerosis in very few people. One reason for this is that the thymus also generates so-called regulatory $\mathrm{CD} 4^{+}$ $\mathrm{T}$ cells - a process coined the "third function" of the thymus (6).

These regulatory $\mathrm{T}$ cells (Treg) develop and are maintained under the control of the transcription factor Foxp3 (7-9). Expression of Foxp3 endows maturing $\mathrm{T}$ cells with an increased robustness toward negative selection (10). Therefore, Foxp $3^{+}$ $\mathrm{CD}^{+}$Treg leaving the thymus display a high degree of autoreactivity $(11,12)$. By employing a wide array of molecular mechansims Treg prevent autoreactive and autoaggressive conventional $\mathrm{CD}^{+} \mathrm{T}^{+}$helper $\left(\mathrm{CD} 4^{+} \mathrm{Tconv}\right)$ and $\mathrm{CD} 8^{+} \mathrm{T}$ cells from attacking healthy tissue which would otherwise lead to autoimmune disease [reviewed in (13)].

In conditions under which a protective adaptive immune response is crucial for the host to survive, mechanisms need to be in place which neutralize Treg-mediated immunosuppression [reviewed in (13)]. A key mechanism here is the recognition of pathogen-associated molecular patterns (PAMPs) via pattern recognition receptors (PRR) like Toll-like receptors expressed by cells of innate immunity like dendritic cells (DC) [reviewed in (14)]. This leads to an upregulation of costimulatory molecules like CD80 and CD86 on the surface of DC, which will trigger CD28 costimulation of $\mathrm{CD} 4^{+}$Tconv. By this they will escape suppression by Treg (15-17). As these signals are spatially and timely restricted, i.e., only present in lymph nodes draining an infection site, Treg-mediated immunosuppression will only be neutralized there, whereas in other tissues Treg will continue to be able to mediate protection from autoimmunity.

Unfortunately, "overshooting" or unwanted adaptive immune responses are not always prevented successfully. This will then lead to different forms of $\mathrm{T}$ [reviewed in (18-20)] or B cellmediated autoimmunity [reviewed in $(21,22)$ ].

Apart from mediating protective immunity and inducing autoimmune diseases causing a substantial amount of morbidity and mortality, $\mathrm{T}$ cells have been recognized to play an important role in maintaining or restoring tissue homeostasis after muscle damage (23), myocardial infarction (24-26) or stroke (27).

To fulfill all these different tasks, T cells in general mainly rely on signals which they receive through cell surface receptors. As such these receptors are, of course, in close contact with lipids forming the cell membrane. About $30 \%$ of phospholipids in the plasma membrane belong to so-called sphingolipids [reviewed in (28)]. The importance of sphingolipids for T cell function stems from the fact that they are not inert molecular species, but that they are subject to metabolization [reviewed in (29)] and are altered depending on the differentiation state and function of the cells. This means e.g., that the most complex sphingolipid sphingomyelin (consisting of a number of species with different fatty acid chain lengths) can be reversibly cleaved into ceramides and phosphocholine (Figure 1). Ceramide molecules have the propensity to self-aggregate, thus, forming so-called ceramiderich platforms [reviewed in (31)]. Ceramides may, however, also be further metabolized into sphingosine and fatty acids. Sphingosine may then be phosphorylated to sphingosine-1phosphate which has very wide-ranging biological activities mediated by a set of five different cell surface receptors, but also by direct interaction with signaling molecules inside cells [reviewed in (32)]. Finally, sphingosine may also be cleaved into phosphoethanolamine and hexadecenal marking the only non-reversible step in sphingolipid metabolism (Figure 1).

The different steps in the meta-(cata-)bolism of sphingomyelin and its breakdown products are catalyzed by a whole array of different enzymes. Localization of these enzymes in different cellular compartments and the modulation of their enzymatic activity upon $\mathrm{T}$ cell activation mean that their biology is very complex. One key mediator of sphingomyelin breakdown is the acid sphingomyelinase (mouse: Asm; human: ASM). In resting T cells the Asm is localized in the inner leaflet of the lysosomal membrane where the presence of $\mathrm{Zn}^{2+}$ ions and the acidic $\mathrm{pH}$ ensure optimal enzymatic activity [reviewed in (29)]. Upon activation of certain cell surface receptors, including CD28 (33) and CD95 (34) via monoclonal antibodies, Asm activity in lysosomes is increased and lysosomes fuse with the cell membrane, thus exposing the Asm on the cell surface where it might still be able to catalyze sphingomyelin cleavage [reviewed in (29)]. Another important sphingomyelinase whose role in $\mathrm{T}$ cell biology is not yet fully understood is the neutral sphingomyelinase 2 (mouse: Nsm2; human: NSM2). In contrast to the Asm, the Nsm2 localizes to the inner leaflet of the plasma membrane and the cytoplasmic side of the Golgi membrane, where it can get activated without being translocated to another cellular compartment (35-38). Stimuli activating the Nsm2 include isolated TCR or TCR and CD28 costimulation via monoclonal antibodies (39).

Apart from meta- and catabolism sphingolipid concentrations in cellular membranes are, of course, also regulated by de novo sphingolipid generation. The "hub" of sphingolipid de novo synthesis is ceramide [reviewed in (30)] with six different ceramide synthases catalyzing the generation of the various ceramide species in the endoplasmic reticulum [reviewed in $(30,40)]$.

\section{CD8 $^{+}$T CELLS}

Having passed thymic selection mature, MHC class I-restricted, $\mathrm{CD}^{+} \mathrm{T}$ cells leave the thymus and migrate to secondary lymphoid organs, i.e., predominantly lymph nodes and spleen. To ensure tight immunological control of the whole body, naïve $\left(\mathrm{CD}^{+}\right) \mathrm{T}$ cells constantly recirculate through the lymphatic/blood system-a process crucially regulated by high concentrations of sphingosine-1-phosphate in efferent lymph and blood [reviewed in (32)].

After encounter of antigen and appropriate costimulation, $\mathrm{CD}^{+} \mathrm{T}$ cells differentiate into cytotoxic T lymphocytes (CTL) expressing lytic granules [reviewed in (41)]. Upon recognition of foreign peptides on MHC class I molecules by the CTL's TCR the CTL will release the content of the lytic granules toward the target cell, i.e., into the synaptic cleft between both cells. Lytic granules contain granzymes and perforin which generates pores in the target cell's membrane through which granzymes can enter the cytoplasm and induce apoptosis by activating caspases [reviewed in (42)]. Upon fusion of the lytic granules with the cell membrane not only proteins like LAMP-1 which is expressed on 


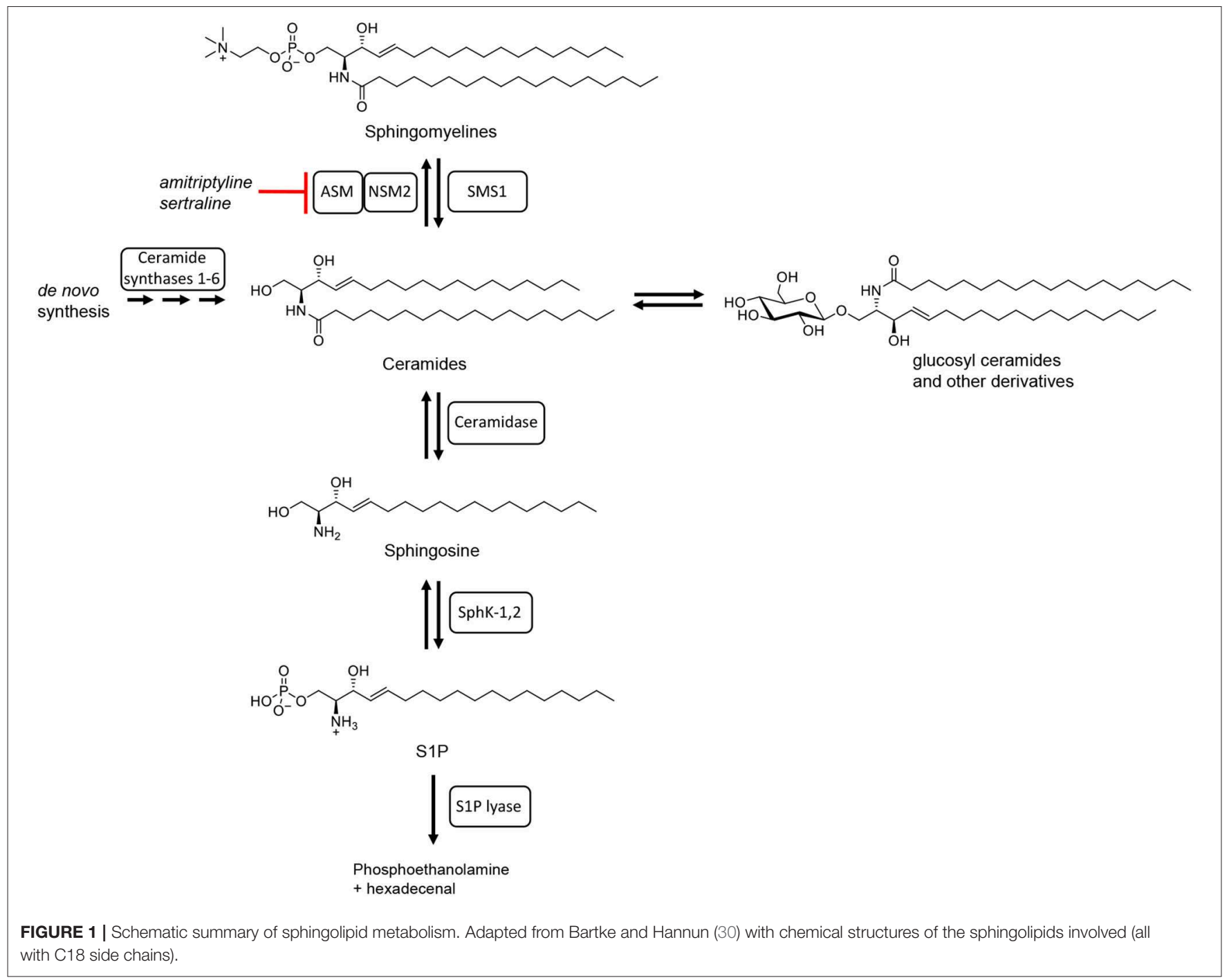

the inner membrane leaflet of lytic vessels and protects CTL and Natural Killer cells from degranulation-associated damage (43), but also the Asm will be exposed on the cell surface [reviewed in $(29,44)]$. Due to the size of the lytic granules sufficient extrusion of their content requires changes to the biophysical properties of their membranes (45). These changes are mediated by the Asm generating ceramide at the inner membrane leaflet of the vesicles. Vesicles containing the chemokine RANTES which also exist in $\mathrm{CD}^{+}$effector $\mathrm{T}$ cells are about 10 -fold smaller than lytic vesicles. Therefore, chemokines are efficiently released from these vesicles even without changes to the biophysical properties of their membranes (45). Reduced release of lytic content from vesicles was associated with reduced killing by CTL from Asmdeficient vs. wild-type mice (45). These data were confirmed by pharmacologically inhibiting Asm activity with imipramine in CTL (45).

Can these insights be used and translated to humans? A direct consequence of the aforementioned observations in mice is that inhibition of Asm activity with clinically approved antidepressants like amitriptyline, imipramine, or sertraline could reduce unwanted CTL activity. This would, of course, lead to unspecific partial immunosuppression. It might, thus, be envisaged as a form of comedication e.g., in patients suffering from pulmonal immunopathology due to overshooting CTL activity against e.g., Influenza A virus-infected alveolar epithelial cells [reviewed in (46)]. In addition to reducing CTL activity, inhibition of the ASM in humans may also directly stabilize pulmonal function as it has been observed in animal models (47-49). In fact it is this latter indication for which ASM inhibitors are currently investigated in children with cystic fibrosis suffering from bacterial infections of the lung (ClinicalTrials.gov Identifier: NCT00515229).

A caveat in the outlined scenario is that, so far, the role of the Asm in lytic granule release from CTL has only been studied in mice. Data for human CD8 ${ }^{+}$CTL are still lacking. As it is very likely that the ASM is also expressed by human $\mathrm{CD}^{+}{ }^{+} \mathrm{T}$ cells it seems plausible that also in humans ASM activity enhances release of cytotoxic content from CTL vesicles. 
Apart from the ASM, the NSM2 also constitutes a therapeutically interesting target to modulate CTL function in humans. This is the case as stimulation of the $\mathrm{T}$ cell receptor complex (with monoclonal antibodies) is sufficient to increase NSM2 activity (39) and for target cell recognition the $\mathrm{CTL}$ only needs to receive an activating signal through the TCR complex. Therefore, inhibition of the NSM2 may also be suitable to reduce unwanted CTL activity.

\section{CONVENTIONAL CD4 ${ }^{+} \mathbf{T}$ CELLS}

Compared to $\mathrm{CD}^{+} \mathrm{T}$ cells and CTL, the body of literature on the impact of sphingolipid metabolism on the function of conventional, i.e., Foxp ${ }^{-}$, non-regulatory T cells (CD4 ${ }^{+}$Tconv) is much bigger (50-52). In particular, researchers have focused in recent years on the modulation of effector cell differentiation and cytokine secretion by human $\mathrm{CD}^{+}{ }^{+} \mathrm{T}$ cells by the ASM $(52,53)$.

An early report comparing cells from Asm-deficient and wildtype mice indicated that secretion of Interleukin-2 (IL-2) by Concanavalin A-stimulated splenocytes among which $\mathrm{CD} 4^{+}$ Tconv are probably the main, followed by $\mathrm{CD} 8^{+} \mathrm{T}$ cells, source of IL-2 [reviewed in (54)], was higher in wild-type than in mutant mice (55). More recently, experiments using human $\mathrm{CD} 4^{+} \mathrm{T}$ cells have revealed a positive role for the ASM in promoting Th17 cell differentiation and IL-17 secretion (52). Here, pharmacological inhibition of the ASM was used to study the impact of the enzyme on $\mathrm{CD}^{+} \mathrm{T}$ cell differentiation and cytokine secretion.

Apart from cytokine secretion, migration of effector/memory $\mathrm{CD} 4^{+}$Tconv also crucially contributes to their function in vivo. Studying mouse $\mathrm{CD} 4^{+} \mathrm{T}$ cells in vitro and in vivo as well as human $\mathrm{CD}^{+} \mathrm{T}$ cells in vitro, it has been recently shown that migration and adhesion to activated endothelial cells requires NSM2 activity (56). Moreover, migration of T cells toward SDF$1 \alpha$, a chemokine recognized by CXCR4, also depends on NSM2 activity (56). Therefore, two crucial steps in CD4 ${ }^{+}$effector cell function, i.e., extravasation at sites of endothelial inflammation, and migration along chemokine gradients necessitates NSM2 activity. For extravasation integrin leukocyte function-associated antigen (LFA)-1 on T cells needs to bind to intercellular adhesion molecule (ICAM)-1 on endothelial cells. Therefore, reduced LFA1 clustering in the absence of NSM2 activity (56) should impact all T cell subsets. Similarly, the broad expression of CXCR4 by $\left(\mathrm{CD}^{+}\right) \mathrm{T}$ cells [reviewed in (57)] also means that targeting NSM2 in T cells affects early as well as advanced stages of $\mathrm{T}$ cell differentiation. Apart from its impact on $\mathrm{T}$ cell migration NSM2 activity also supports early signaling events in Jurkat and primary human $\mathrm{CD}^{+} \mathrm{T}$ cells (58). In the absence of NSM2 activity, T cell receptor signaling is initiated as in wildtype $\mathrm{T}$ cells, but signaling is not sustained due to deficient protein kinase $\mathrm{C}_{5}$ activation. Together, this means that the NSM2 might qualify as a novel therapeutic target for suppressing unwanted immune responses. Currently, there is, however, no data concerning the immunomodulatory activities of NSM2 inhibitors in humans in vivo.
Another critical aspect of $\mathrm{T}$ cell biology is the tight homeostatic control of the compartment size through induction of different forms of cell death [reviewed in (59)]. Most notably, activation of naïve $\left(\mathrm{CD}^{+}\right) \mathrm{T}$ cells is followed by massive expansion of reactive clones. After resolution of inflammation the effector $\mathrm{T}$ cell pool again collapses with only few memory $\mathrm{T}$ cells surviving long-term [reviewed in $(60,61)]$. The collapse of the acute immune response is due to different mechanisms of cell death with apoptosis induction by Fas (CD95)-Fas ligand being the best studied pathway, but other forms of cell death like necroptosis are increasingly recognized to also play a role here [reviewed in $(59,62)]$. Ligation of Fas on activated T cells stimulates Asm activity leading to ceramide production and, as a consequence, to the induction of cell death (63-65). Therefore, and even more generally, ceramide production has been linked to induction of cell death [reviewed in (29)]. Seemingly in contrast to this notion we observed that pharmacological inhibitors of the Asm also induced cell death in Tconv of mice (66) and at slightly higher concentrations also in human $\mathrm{CD} 4^{+}$Tconv (Dennstaedt, Schneider-Schaulies, Beyersdorf, unpublished). The availability of Asm-deficient mice allowed to confirm that cell death induced by amitriptyline or desipramine was due to their impact on the Asm and not the acid ceramidase which they also inhibit $(66,67)$. This has, as discussed in the following paragraph, an impact on the balance of $\mathrm{CD} 4^{+}$Tconv and Treg.

In patients treated with antidepressants inhibiting ASM activity like amitriptyline or sertraline (68) no $\left(\mathrm{CD}^{+}\right)$ lymphopenia has been reported. This might be due to the relatively low concentrations of ASM-inhibiting antidepressants in peripheral blood of humans (about $1 \mu \mathrm{M}$ ) (69). In secondary lymphoid organs it is, however, assumed that up to 10 -fold higher concentrations are reached (69). As ASM inhibitors are sufficient to kill human $\mathrm{CD}^{+}{ }^{+}$Tconv in vitro this indicates that ASM inhibitors might also induce cell death in human $\mathrm{CD}_{4}^{+}$ Tconv in secondary lymphoid organs in vivo. For mice we had observed that the negative effects on $\mathrm{CD} 4{ }^{+}$Tconv cell numbers in spleen and lymph nodes after Asm inhibition in vivo were less pronounced than after in vitro treatment of mouse $\mathrm{T}$ cells (66). Similar to patients, serum concentrations of amitriptyline in these mice were also in the order of $1 \mu \mathrm{M}$ (70). This might indicate that there are pro-survival factors present in vivo which were lacking in the in vitro cell cultures. But despite such putatively beneficial factors, a reduction in $\mathrm{CD} 4^{+}$Tconv numbers in spleens and less so in lymph nodes was observed (66), which is best explained by induction of cell death in a fraction of these cells. Therefore, in humans in vivo $\mathrm{CD} 4^{+}$Tconv depletion might also take place on a small scale. Due to the long-term use of antidepressants by patients and the very low output rate of the thymus in adults (71) it may well be that these patients gradually become lymphopenic over time.

\section{TREG}

Treg differ from $\mathrm{CD}^{+}{ }^{+}$Tconv and $\mathrm{CD}^{+} \mathrm{T}$ cells in that, due to their autoreactivity $(11,12)$, they constantly receive activating signals through their $\mathrm{T}$ cell receptor-even in healthy subjects. 
Apart from the $\mathrm{T}$ cell receptor, signaling through $\mathrm{CD} 28$ and the high affinity IL-2 receptor are crucial to maintain Treg numbers and function (72-77). For CD28 it has been shown that ligation with monoclonal antibodies strongly increases ASM activity in human $\mathrm{T}$ cells (33). In line with their dependence on CD28 signaling for survival, both mouse (66) and human Treg (Dennstaedt, Schneider-Schaulies, Beyersdorf, unpublished) show constitutively higher ASM activity than $\mathrm{CD}^{+}$Tconv and for mouse Treg it has been shown that they also contain increased amounts of ceramide compared to $\mathrm{CD} 4^{+}$ Tconv $(66,78)$.

Apart from the Asm, underexpression of the sphingomyelin synthase 1 (Sms1) in Treg vs. CD4 ${ }^{+}$Tconv contributes to the increased ceramide content of Treg vs. $\mathrm{CD} 4^{+}$Tconv (78). The increase in ceramide induced by this lack of Sms1 maintains suppression of the Akt/mTOR pathway in Treg through the phosphatase PP2A. Suppression of Akt/mTOR signaling is crucial for Treg to be able to inhibit CD4 ${ }^{+}$Tconv (78).

Currently, it is unclear whether or how much the ceramide pools regulated by Asm and Sms1 activity overlap. This is of importance as for the activation of the phosphatase PP2A its inhibitor SET needs to bind to ceramide (79). The Asm is expressed in the inner leaflet of the lysosomal membrane and translocates to the outer leaflet of the cell membrane upon $\mathrm{T}$ cell activation and fusion of the lsysome with the cell membrane. Therefore, Asm activity generates ceramide in the inner leaflet of the lysosome and the outer leaflet of the cell membrane. However, ceramide spontaneously flips from one membrane leaflet to the other and for other sphingolipid species "filppase"-mediated exchange between membrane leaflets has been described [reviewed in (29)]. As ceramide generated by the Asm may, thus, also accumulate in the cytosolic leaflet of membranes Asm activity might enhance PP2A activity in Treg. Genetic deficiency for the Asm in mice led to an increase in the proportion of Treg among $\mathrm{CD}^{+} \mathrm{T}$ cells (66), which would be in line with this hypothesis. However, the suppressive activity of Treg was increased on a per-call basis as read out in surrogate in vitro suppression assays (66). This suggest that ceramide generated by the Asm may not be critical for PP2A activity as otherwise suppression by Treg would have been lost (78). More definite conclusions regarding the ceramide pools regulated by the Asm vs. the Sms1 are not possible as the changes in sphingolipid composition in cells of Asm-deficient compared to wildtype mice are very complex. Despite their Asm deficiency, $\mathrm{T}$ cells, and other cells, display strongly increased ceramide levels $(66,80,81)$. In parallel, the sphingomyelin content of these cells is even further increased $(66,80,81)$. This means that the substrate/product ratio for the Asm is reduced in these animals as might be expected due to the Asm deficiency. However, it is currently unclear what exactly drives the changes we observed in these animals with regard to Treg: Whether it is the overall amount of sphingolipids found in these cells or whether it is the sphingolipid composition of membranes.

For Treg a plethora of different molecular mechanisms has been described by which they might inhibit other $\mathrm{T}$ cells [reviewed in (13)]. A crucial effector molecule, mediating cell contact-dependent suppression by Treg is the checkpoint molecule CTLA-4 (82-85). Being strongly activated we observed higher CTLA-4 expression in Treg of Asm-deficient vs. wildtype mice (66). CTLA-4 functions as an immune checkpoint by removing costimulatory molecules from the surface of antigenpresenting cells like dendritic cells or B cells $(83,84)$. This process is called transendocytosis. As the costimulatory receptor CD28 and CTLA-4 share the ligands CD80 and CD86, CTLA-4-mediated transendocytosis leads to a net reduction in $\mathrm{T}$ cell costimulation and, thus, immunosuppression. During transendocytosis, the complex of CTLA-4 and bound ligand is internalized and degraded within the lysosome [reviewed in (84)]. In fact, endo-lysosomal vesicles contain the vast majority of CTLA-4 molecules expressed by a T cell under steady-state conditions. Only upon activation CTLA-4 surface expression is increased, primarily within the immunological synapse (86). The low CTLA-4 surface expression is the consequence of shuttling from endo-lysosomal compartments to the cell surface followed by rapid internalization in the absence of ligand binding [reviewed in (84)]. Therefore, the biological activity of CTLA-4 is governed by this complex expression pattern. Using a so-called "capture assay" we monitored CTLA- 4 turn-over between the cell membrane and cellular compartments in Treg from wild-type and Asm-deficient mice (66). Here, we observed that Treg from Asm-deficient mice showed a higher turn-over than Treg from wild-type mice.

For human Treg we used pharmacological inhibitors of the ASM to study its impact on CTLA-4 function and turn-over. We observed that inhibition of the ASM in human Treg increased CTLA-4 turn-over as observed in Treg from Asm-deficient mice (Wiese, Schneider-Schaulies, Beyersdorf, unpublished). Therefore, both in mouse and in human Treg, ASM activity is important for the turn-over of CTLA-4.

Although Treg generation is the "third function" of the thymus, Treg may also differentiate from $\mathrm{CD}^{+}$Tconv in mice under certain conditions (87). The generation of socalled peripherally induced Treg ( $\mathrm{pTreg}$ ) is thought to be of particular importance for immunity in humans [reviewed in (88)]. The identification of two distinct thymic Treg precursors in mice expressing predominantly self-reactive TCRs and TCRs with reactivity to foreign antigen (12), however, challenges this concept and might pinpoint to the thymus as the sole source of bona fide Treg also in humans. Together these findings mean that by studying conditions under which $\mathrm{pTreg}$ can be generated from $\mathrm{CD}^{+}$Tconv in vitro one analyses the impact of certain factors primarily on the stability of the Treg lineage. Using such in vitro systems it was observed that Asm activity has a supportive effect for pTreg generation from Tconv (89).

\section{OUTLOOK}

Up to now antidepressants inhibiting ASM activity are the most widely applied drugs in humans directly impacting on ceramide generation from sphingomyelin (prevalence depression: 5,000/100,000) (90). As these drugs not only induce degradation of the ASM, but also the acid ceramidase (67), more specific direct inhibitors would be clinically desirable. 
With bisphosphonates such as zoledronate, which are used for the treatment of osteoporosis (prevalence: about 5,000/100,000 in people in their fifties and 25,000/100,000 in octogenerians) (91), safe drugs are available that directly inhibit ASM activity. Currently, it is, however, unclear whether bisphosphonates, including the very potent ASM inhibitor ARC39 (92, 93), will also modulate ASM activity in T cells in vivo or whether their high degree of binding to bone surfaces and osteoclasts prohibits sufficient drug levels in secondary lymphoid organs to modulate T cell activity.

The data obtained on the contribution of ASM and NSM2 activity to $\mathrm{T}$ cell function in preclinical mouse models and with human T cells in vitro all suggest that pharmacologically blocking these enzymes will either directly or, through biasing the $\mathrm{CD} 4^{+} \mathrm{T}$ cell compartment toward Treg, indirectly impair T cell function. Therefore, a potential novel indication for the use of ASM or possibly also NSM2 inhibitors might be autoimmune diseases such as multiple sclerosis (prevalence: about 100/100,000) (94, 95). As discussed, overshooting immunity in the course of e.g., an influenza A virus infection may constitute another potential novel application for ASM inhibitors.

As sphingomyelinase deficiency impairs $\mathrm{T}$ cell function boosting sphingomyelinase activity might increase their function which could improve e.g., anti-cancer immunity. Indeed, it has recently been shown that $\mathrm{T}$ cell-specific overexpression of the ASM leads to enhanced T cell-mediated immunity against the parasite Plasmodium yoelii (96). This suggests that also in humans increasing ASM activity in T cells might enhance T

\section{REFERENCES}

1. Klein L, Kyewski B, Allen PM, Hogquist KA. Positive and negative selection of the T cell repertoire: what thymocytes see (and don't see). Nat Rev Immunol. (2014) 14:377-91. doi: 10.1038/nri3667

2. Ota K, Matsui M, Milford EL, Mackin GA, Weiner HL, Hafler DA. T-cell recognition of an immunodominant myelin basic protein epitope in multiple sclerosis. Nature. (1990) 346:183-7. doi: 10.1038/346183a0

3. Zhang J, Markovic-Plese S, Lacet B, Raus J, Weiner HL, Hafler DA. Increased frequency of interleukin 2-responsive $\mathrm{T}$ cells specific for myelin basic protein and proteolipid protein in peripheral blood and cerebrospinal fluid of patients with multiple sclerosis. J Exp Med. (1994) 179:973-84. doi: 10.1084 /jem.179.3.973

4. Scholz C, Patton KT, Anderson DE, Freeman GJ, Hafler DA. Expansion of autoreactive $\mathrm{T}$ cells in multiple sclerosis is independent of exogenous B7 costimulation. J Immunol. (1998) 160:1532-8.

5. Cao Y, Goods BA, Raddassi K, Nepom GT, Kwok WW, Love JC, et al. Functional inflammatory profiles distinguish myelin-reactive $\mathrm{T}$ cells from patients with multiple sclerosis. Sci Transl Med. (2015) 7:287ra274. doi: 10.1126/scitranslmed.aaa8038

6. Seddon B, Mason D. The third function of the thymus. Immunol Today. (2000) 21:95-9. doi: 10.1016/S0167-5699(99)01559-5

7. Fontenot JD, Gavin MA, Rudensky AY. Foxp3 programs the development and function of $\mathrm{CD} 4{ }^{+} \mathrm{CD} 25^{+}$regulatory T cells. Nat Immunol. (2003) 4:330-6. doi: $10.1038 /$ ni904

8. Hori S, Nomura T, Sakaguchi S. Control of regulatory T cell development by the transcription factor Foxp3. Science. (2003) 299:1057-61. doi: 10.1126/science. 1079490

9. Walker MR, Kasprowicz DJ, Gersuk VH, Benard A, Van Landeghen M, Buckner JH, et al. Induction of FoxP3 and acquisition of T regulatory activity cell-mediated immunity. Therefore, future research should focus on identifying suitable drugs for increasing ASM activity in human T cells.

Growing knowledge on the role of sphingolipid metabolism in $\mathrm{T}$ cell biology fuelled by the generation of novel inducible knockout mouse models as well as novel analytical tools will help to define more potential therapeutic targets. For these, either small molecule or monoclonal antibody-based therapies may allow for specific targeting.

\section{DATA AVAILABILITY STATEMENT}

All datasets generated for this study are included in the manuscript/supplementary files.

\section{AUTHOR CONTRIBUTIONS}

$\mathrm{CH}$, TW, and FD generated data and edited the paper. JF designed figures. JS-S designed figures and edited the paper. NB wrote the paper.

\section{FUNDING}

This work has been funded by grants from the Deutsche Forschungsgemeinschaft (FOR2123/P02 and Z01). The publication as such was funded by the German Research Foundation (DFG) and the University of Würzburg in the funding programme Open Access Publishing. by stimulated human $\mathrm{CD}^{+} \mathrm{CD} 25^{-} \mathrm{T}$ cells. J Clin Invest. (2003) 112:1437-43. doi: 10.1172/JCI19441

10. van Santen HM, Benoist C, Mathis D. Number of T reg cells that differentiate does not increase upon encounter of agonist ligand on thymic epithelial cells. J Exp Med. (2004) 200:1221-30. doi: 10.1084/jem.20041022

11. Hsieh CS, Liang Y, Tyznik AJ, Self SG, Liggitt D, Rudensky AY. Recognition of the peripheral self by naturally arising $\mathrm{CD} 25^{+} \mathrm{CD} 4^{+} \mathrm{T}$ cell receptors. Immunity. (2004) 21:267-77. doi: 10.1016/j.immuni.2004.07.009

12. Owen DL, Mahmud SA, Sjaastad LE, Williams JB, Spanier JA, Simeonov $\mathrm{DR}$, et al. Thymic regulatory $\mathrm{T}$ cells arise via two distinct developmental programs. Nat Immunol. (2019) 20:195-205. doi: 10.1038/s41590-018-02 $89-6$

13. Yamaguchi T, Wing JB, Sakaguchi S. Two modes of immune suppression by Foxp $3\left({ }^{+}\right)$regulatory $\mathrm{T}$ cells under inflammatory or non-inflammatory conditions. Semin Immunol. (2011) 23:424-30. doi: 10.1016/j.smim.2011.10.002

14. Joffre O, Nolte MA, Sporri R, Reis e Sousa C. Inflammatory signals in dendritic cell activation and the induction of adaptive immunity. Immunol Rev. (2009) 227:234-47. doi: 10.1111/j.1600-065X.2008.00718.x

15. Thornton AM, Shevach EM. $\mathrm{CD} 4^{+} \mathrm{CD} 25^{+}$immunoregulatory $\mathrm{T}$ cells suppress polyclonal $\mathrm{T}$ cell activation in vitro by inhibiting interleukin 2 production. J Exp Med. (1998) 188:287-96. doi: 10.1084/jem.188. 2.287

16. Thornton AM, Donovan EE, Piccirillo CA, Shevach EM. Cutting edge: IL-2 is critically required for the in vitro activation of $\mathrm{CD} 4{ }^{+} \mathrm{CD} 25^{+} \mathrm{T}$ cell suppressor function. J Immunol. (2004) 172:6519-23. doi: 10.4049/jimmunol.172.11.6519

17. Beyersdorf N, Balbach K, Hunig T, Kerkau T. Large-scale expansion of rat $\mathrm{CD}^{+} \mathrm{CD}^{+} 5^{+} \mathrm{T}(\mathrm{reg})$ cells in the absence of $\mathrm{T}$-cell receptor stimulation. Immunology. (2006) 119:441-50. doi: 10.1111/j.1365-2567.2006. 02455.x 
18. Fletcher JM, Lalor SJ, Sweeney CM, Tubridy N, Mills KH. T cells in multiple sclerosis and experimental autoimmune encephalomyelitis. Clin Exp Immunol. (2010) 162:1-11. doi: 10.1111/j.1365-2249.2010.04143.x

19. Pugliese A. Autoreactive $T$ cells in type 1 diabetes. J Clin Invest. (2017) 127:2881-91. doi: 10.1172/JCI94549

20. Imam T, Park S, Kaplan MH, Olson MR. Effector $T$ helper cell subsets in inflammatory bowel diseases. Front Immunol. (2018) 9:1212. doi: 10.3389/fimmu.2018.01212

21. McInnes IB, Schett G. The pathogenesis of rheumatoid arthritis. N Engl J Med. (2011) 365:2205-19. doi: 10.1056/NEJMra1004965

22. Tsokos GC. Systemic lupus erythematosus. N Engl J Med. (2011) 365:2110-21. doi: 10.1056/NEJMra1100359

23. Burzyn D, Kuswanto W, Kolodin D, Shadrach JL, Cerletti M, Jang Y, et al. A special population of regulatory T cells potentiates muscle repair. Cell. (2013) 155:1282-95. doi: 10.1016/j.cell.2013.10.054

24. Tang TT, Yuan J, Zhu ZF, Zhang WC, Xiao H, Xia N, et al. Regulatory T cells ameliorate cardiac remodeling after myocardial infarction. Basic Res Cardiol. (2012) 107:232. doi: 10.1007/s00395-011-0232-6

25. Weirather J, Hofmann UD, Beyersdorf N, Ramos GC, Vogel B, Frey A, et al. Foxp $3^{+} \mathrm{CD}^{+} \mathrm{T}$ cells improve healing after myocardial infarction by modulating monocyte/macrophage differentiation. Circ Res. (2014) 115:5567. doi: 10.1161/CIRCRESAHA.115.303895

26. Zeng Z, Yu K, Chen L, Li W, Xiao H, Huang Z. Interleukin-2/anti-interleukin2 immune complex attenuates cardiac remodeling after myocardial infarction through expansion of regulatory T cells. J Immunol Res. (2016) 2016:8493767. doi: 10.1155/2016/8493767

27. Na SY, Mracsko E, Liesz A, Hunig T, Veltkamp R. Amplification of regulatory $\mathrm{T}$ cells using a CD28 superagonist reduces brain damage after ischemic stroke in mice. Stroke. (2015) 46:212-20. doi: 10.1161/STROKEAHA.114.007756

28. van Meer G, Voelker DR, Feigenson GW. Membrane lipids: where they are and how they behave. Nat Rev Mol Cell Biol. (2008) 9:112-24. doi: $10.1038 / \mathrm{nrm} 2330$

29. Hannun YA, Obeid LM. Sphingolipids and their metabolism in physiology and disease. Nat Rev Mol Cell Biol. (2018) 19:175-91. doi: 10.1038/nrm.2017.107

30. Bartke N, Hannun YA. Bioactive sphingolipids: metabolism and function. $J$ Lipid Res. (2009) 50:S91-6. doi: 10.1194/jlr.R800080-JLR200

31. Milhas D, Clarke CJ, Hannun YA. Sphingomyelin metabolism at the plasma membrane: implications for bioactive sphingolipids. FEBS Lett. (2010) 584:1887-94. doi: 10.1016/j.febslet.2009.10.058

32. Spiegel S, Milstien S. The outs and the ins of sphingosine-1-phosphate in immunity. Nat Rev Immunol. (2011) 11:403-15. doi: 10.1038/nri2974

33. Boucher LM, Wiegmann K, Futterer A, Pfeffer K, Machleidt T, Schutze S, et al. CD28 signals through acidic sphingomyelinase. J Exp Med. (1995) 181:2059-68. doi: 10.1084/jem.181.6.2059

34. Cifone MG, De Maria R, Roncaioli P, Rippo MR, Azuma M, Lanier LL, et al. Apoptotic signaling through CD95 (Fas/Apo-1) activates an acidic sphingomyelinase. J Exp Med. (1994) 180:1547-52. doi: $10.1084 /$ jem.180.4.1547

35. Hofmann K, Tomiuk S, Wolff G, Stoffel W. Cloning and characterization of the mammalian brain-specific, $\mathrm{Mg}^{2+}$-dependent neutral sphingomyelinase. Proc Natl Acad Sci USA. (2000) 97:5895-900. doi: 10.1073/pnas.97.11.5895

36. Milhas D, Clarke CJ, Idkowiak-Baldys J, Canals D, Hannun YA. Anterograde and retrograde transport of neutral sphingomyelinase-2 between the Golgi and the plasma membrane. Biochim Biophys Acta. (2010) 1801:1361-74. doi: 10.1016/j.bbalip.2010.08.001

37. Stoffel W, Hammels I, Jenke B, Binczek E, Schmidt-Soltau I, Brodesser $\mathrm{S}$, et al. Neutral sphingomyelinase (SMPD3) deficiency disrupts the Golgi secretory pathway and causes growth inhibition. Cell Death Dis. (2016) 7:e2488. doi: 10.1038/cddis.2016.385

38. Back MJ, Ha HC, Fu Z, Choi JM, Piao Y, Won JH, et al. Activation of neutral sphingomyelinase 2 by starvation induces cell-protective autophagy via an increase in Golgi-localized ceramide. Cell Death Dis. (2018) 9:670. doi: 10.1038/s41419-018-0709-4

39. Mueller N, Avota E, Collenburg L, Grassme H, Schneider-Schaulies S. Neutral sphingomyelinase in physiological and measles virus induced $\mathrm{T}$ cell suppression. PLoS Pathog. (2014) 10:e1004574. doi: 10.1371/journal.ppat.1004574
40. Cingolani F, Futerman AH, Casas J. Ceramide synthases in biomedical research. Chem Phys Lipids. (2016) 197:25-32. doi: 10.1016/j.chemphyslip.2015.07.026

41. Wherry EJ, Ahmed R. Memory CD8 T-cell differentiation during viral infection. J Virol. (2004) 78:5535-45. doi: 10.1128/JVI.78.11.5535-5545.2004

42. van den Brink MR, Burakoff SJ. Cytolytic pathways in haematopoietic stemcell transplantation. Nat Rev Immunol. (2002) 2:273-81. doi: 10.1038/nri775

43. Cohnen A, Chiang SC, Stojanovic A, Schmidt H, Claus M, Saftig $\mathrm{P}$, et al. Surface CD107a/LAMP-1 protects natural killer cells from degranulation-associated damage. Blood. (2013) 122:1411-8. doi: 10.1182/blood-2012-07-441832

44. Jenkins MR, Griffiths GM. The synapse and cytolytic machinery of cytotoxic T cells. Curr Opin Immunol. (2010) 22:308-13. doi: 10.1016/j.coi.2010.02.008

45. Herz J, Pardo J, Kashkar H, Schramm M, Kuzmenkina E, Bos E, et al. Acid sphingomyelinase is a key regulator of cytotoxic granule secretion by primary T lymphocytes. Nat Immunol. (2009) 10:761-8. doi: 10.1038/ni. 1757

46. Duan S, Thomas PG. Balancing immune protection and immune pathology by CD8(+) T-cell responses to influenza infection. Front Immunol. (2016) 7:25. doi: 10.3389/fimmu.2016.00025

47. von Bismarck P, Wistadt CF, Klemm K, Winoto-Morbach S, Uhlig U, Schutze $\mathrm{S}$, et al. Improved pulmonary function by acid sphingomyelinase inhibition in a newborn piglet lavage model. Am J Respir Crit Care Med. (2008) 177:123341. doi: $10.1164 / \mathrm{rccm} .200705-752 \mathrm{OC}$

48. Peng H, Li C, Kadow S, Henry BD, Steinmann J, Becker KA, et al. Acid sphingomyelinase inhibition protects mice from lung edema and lethal Staphylococcus aureus sepsis. J Mol Med. (2015) 93:675-89. doi: 10.1007/s00109-014-1246-y

49. Pandolfi R, Barreira B, Moreno E, Lara-Acedo V, Morales-Cano D, MartinezRamas A, et al. Role of acid sphingomyelinase and IL- 6 as mediators of endotoxin-induced pulmonary vascular dysfunction. Thorax. (2017) 72:46071. doi: 10.1136/thoraxjnl-2015-208067

50. Miguel L, Owen DM, Lim C, Liebig C, Evans J, Magee AI, et al. Primary human $\mathrm{CD}^{+} \mathrm{T}$ cells have diverse levels of membrane lipid order that correlate with their function. J Immunol. (2011) 186:3505-16. doi: 10.4049/jimmunol.1002980

51. Bai A, Moss A, Kokkotou E, Usheva A, Sun X, Cheifetz A, et al. CD39 and CD161 modulate Th17 responses in Crohn's disease. J Immunol. (2014) 193:3366-77. doi: 10.4049/jimmunol.1400346

52. Bai A, Kokkotou E, Zheng Y, Robson SC. Role of acid sphingomyelinase bioactivity in human $\mathrm{CD} 4^{+}$T-cell activation and immune responses. Cell Death Dis. (2015) 6:e1828. doi: 10.1038/cddis.2015.178

53. Bai A, Guo Y. Acid sphingomyelinase mediates human CD4(+) T-cell signaling: potential roles in T-cell responses and diseases. Cell Death Dis. (2017) 8:e2963. doi: 10.1038/cddis. 2017.360

54. Kalia V, Sarkar S. Regulation of effector and memory CD8 T cell differentiation by IL-2-a balancing act. Front Immunol. (2018) 9:2987. doi: 10.3389/fimmu.2018.02987

55. Stoffel B, Bauer P, Nix M, Deres K, Stoffel W. Ceramide-independent CD28 and TCR signaling but reduced IL-2 secretion in T cells of acid sphingomyelinase-deficient mice. Eur J Immunol. (1998) 28:874-80. doi: 10. 1002/(SICI) 1521-4141(199803)28:03<874::AID-IMMU874>3.0.CO;2-T

56. Collenburg L, Beyersdorf N, Wiese T, Arenz C, Saied EM, Becker-Flegler $\mathrm{KA}$, et al. The activity of the neutral sphingomyelinase is important in $\mathrm{T}$ cell recruitment and directional migration. Front Immunol. (2017) 8:1007. doi: 10.3389/fimmu.2017.01007

57. Murdoch C. CXCR4: chemokine receptor extraordinaire. Immunol Rev. (2000) 177:175-84. doi: 10.1034/j.1600-065X.2000.17715.x

58. Bortlein C, Draeger A, Schoenauer R, Kuhlemann A, Sauer M, SchneiderSchaulies $S$, et al. The neutral sphingomyelinase 2 is required to polarize and sustain T cell receptor signaling. Front Immunol. (2018) 9:815. doi: 10.3389/fimmu.2018.00815

59. Zhan Y, Carrington EM, Zhang Y, Heinzel S, Lew AM. Life and death of activated T cells: how are they different from naive T cells? Front Immunol. (2017) 8:1809. doi: 10.3389/fimmu.2017.01809

60. MacLeod MK, Kappler JW, Marrack P. Memory CD4 T cells: generation, reactivation and re-assignment. Immunology. (2010) 130:10-5. doi: 10.1111/j.1365-2567.2010.03260.x 
61. Farber DL, Yudanin NA, Restifo NP. Human memory T cells: generation, compartmentalization and homeostasis. Nat Rev Immunol. (2014) 14:24-35. doi: 10.1038/nri3567

62. Marrack P, Scott-Browne J, MacLeod MK. Terminating the immune response. Immunol Rev. (2010) 236:5-10. doi: 10.1111/j.1600-065X.2010.00928.x

63. Kirschnek S, Paris F, Weller M, Grassme H, Ferlinz K, Riehle A, et al. CD95mediated apoptosis in vivo involves acid sphingomyelinase. J Biol Chem. (2000) 275:27316-23. doi: 10.1074/jbc.M002957200

64. Grassme H, Cremesti A, Kolesnick R, Gulbins E. Ceramide-mediated clustering is required for CD95-DISC formation. Oncogene. (2003) 22:545770. doi: 10.1038/sj.onc.1206540

65. Gulbins E. Regulation of death receptor signaling and apoptosis by ceramide. Pharmacol Res. (2003) 47:393-9. doi: 10.1016/S1043-6618(03)00052-5

66. Hollmann C, Werner S, Avota E, Reuter D, Japtok L, Kleuser B, et al. Inhibition of acid sphingomyelinase allows for selective targeting of CD4 ${ }^{+}$ conventional versus Foxp3 ${ }^{+}$regulatory T cells. J Immunol. (2016) 197:313041. doi: 10.4049/jimmunol.1600691

67. Elojeimy S, Holman DH, Liu X, El-Zawahry A, Villani M, Cheng JC, et al. New insights on the use of desipramine as an inhibitor for acid ceramidase. FEBS Lett. (2006) 580:4751-6. doi: 10.1016/j.febslet.2006.07.071

68. Kornhuber J, Muehlbacher M, Trapp S, Pechmann S, Friedl A, Reichel M, et al. Identification of novel functional inhibitors of acid sphingomyelinase. PLoS ONE. (2011) 6:e23852. doi: 10.1371/journal.pone.0023852

69. Gobin V, Van Steendam K, Denys D, Deforce D. Selective serotonin reuptake inhibitors as a novel class of immunosuppressants. Int Immunopharmacol. (2014) 20:148-56. doi: 10.1016/j.intimp.2014.02.030

70. Hollmann C. Role of the acid sphingomyelinase in anti-viral $T$ cell responses in a measles virus infection model (Ph.D. thesis). University of Würzburg, Würzburg (2017).

71. den Braber I, Mugwagwa T, Vrisekoop N, Westera L, Mogling R, de Boer $\mathrm{AB}$, et al. Maintenance of peripheral naive $\mathrm{T}$ cells is sustained by thymus output in mice but not humans. Immunity. (2012) 36:288-97. doi: 10.1016/j.immuni.2012.02.006

72. Salomon B, Lenschow DJ, Rhee L, Ashourian N, Singh B, Sharpe A, et al. B7/CD28 costimulation is essential for the homeostasis of the CD4 ${ }^{+} \mathrm{CD} 25^{+}$ immunoregulatory $\mathrm{T}$ cells that control autoimmune diabetes. Immunity. (2000) 12:431-40. doi: 10.1016/S1074-7613(00)80195-8

73. Tang Q, Henriksen KJ, Boden EK, Tooley AJ, Ye J, Subudhi SK, et al. Cutting edge: $\mathrm{CD} 28$ controls peripheral homeostasis of $\mathrm{CD} 4{ }^{+} \mathrm{CD} 25^{+}$regulatory $\mathrm{T}$ cells. J Immunol. (2003) 171:3348-52. doi: 10.4049/jimmunol.171.7.3348

74. D'Cruz LM, Klein L. Development and function of agonist-induced $\mathrm{CD}_{25}{ }^{+} \mathrm{Foxp}^{+}{ }^{+}$regulatory $\mathrm{T}$ cells in the absence of interleukin 2 signaling. Nat Immunol. (2005) 6:1152-9. doi: 10.1038/ni1264

75. Fontenot JD, Rasmussen JP, Gavin MA, Rudensky AY. A function for interleukin 2 in Foxp3-expressing regulatory T cells. Nat Immunol. (2005) 6:1142-51. doi: 10.1038/ni1263

76. Gogishvili T, Luhder F, Goebbels S, Beer-Hammer S, Pfeffer K, Hunig T. Cell-intrinsic and -extrinsic control of Treg-cell homeostasis and function revealed by induced CD28 deletion. Eur J Immunol. (2013) 43:188-93. doi: 10.1002/eji.201242824

77. Zhang R, Huynh A, Whitcher G, Chang J, Maltzman JS, Turka LA. An obligate cell-intrinsic function for CD28 in Tregs. J Clin Invest. (2013) 123:580-93. doi: 10.1172/JCI65013

78. Apostolidis SA, Rodriguez-Rodriguez N, Suarez-Fueyo A, Dioufa N, Ozcan E, Crispin JC, et al. Phosphatase PP2A is requisite for the function of regulatory T cells. Nat Immunol. (2016) 17:556-64. doi: 10.1038/ni.3390

79. Mukhopadhyay A, Saddoughi SA, Song P, Sultan I, Ponnusamy S, Senkal CE, et al. Direct interaction between the inhibitor 2 and ceramide via sphingolipidprotein binding is involved in the regulation of protein phosphatase $2 \mathrm{~A}$ activity and signaling. FASEB J. (2009) 23:751-63. doi: 10.1096/fj.08-120550

80. Horinouchi K, Erlich S, Perl DP, Ferlinz K, Bisgaier CL, Sandhoff K, et al. Acid sphingomyelinase deficient mice: a model of types A and B Niemann-Pick disease. Nat Genet. (1995) 10:288-93. doi: 10.1038/ng0795-288
81. Schuchman EH, Wasserstein MP. Types A and B Niemann-Pick disease. Best Pract Res Clin Endocrinol Metab. (2015) 29:237-47. doi: 10.1016/j.beem.2014.10.002

82. Wing K, Onishi Y, Prieto-Martin P, Yamaguchi T, Miyara M, Fehervari Z, et al. CTLA-4 control over Foxp $3^{+}$regulatory T cell function. Science. (2008) 322:271-5. doi: 10.1126/science.1160062

83. Qureshi OS, Zheng Y, Nakamura K, Attridge K, Manzotti C, Schmidt EM, et al. Trans-endocytosis of CD80 and CD86: a molecular basis for the cell-extrinsic function of CTLA-4. Science. (2011) 332:600-3. doi: 10.1126/science.120 2947

84. Walker LS, Sansom DM. The emerging role of CTLA4 as a cell-extrinsic regulator of $\mathrm{T}$ cell responses. Nat Rev Immunol. (2011) 11:852-63. doi: $10.1038 /$ nri3108

85. Hou TZ, Qureshi OS, Wang CJ, Baker J, Young SP, Walker LS, et al. A transendocytosis model of CTLA-4 function predicts its suppressive behavior on regulatory $\mathrm{T}$ cells. J Immunol. (2015) 194:2148-59. doi: 10.4049/jimmunol.1401876

86. Pentcheva-Hoang T, Egen JG, Wojnoonski K, Allison JP. B7-1 and B72 selectively recruit CTLA-4 and CD28 to the immunological synapse. Immunity. (2004) 21:401-13. doi: 10.1016/j.immuni.2004.06.017

87. Kretschmer K, Apostolou I, Hawiger D, Khazaie K, Nussenzweig MC, von Boehmer $\mathrm{H}$. Inducing and expanding regulatory $\mathrm{T}$ cell populations by foreign antigen. Nat Immunol. (2005) 6:1219-27. doi: 10.1038/ni1265

88. Akbar AN, Vukmanovic-Stejic M, Taams LS, Macallan DC. The dynamic coevolution of memory and regulatory $\mathrm{CD}^{+} \mathrm{T}$ cells in the periphery. Nat Rev Immunol. (2007) 7:231-7. doi: 10.1038/nri2037

89. Zhou Y, Salker MS, Walker B, Munzer P, Borst O, Gawaz M, et al. Acid sphingomyelinase (ASM) is a negative regulator of regulatory $\mathrm{T}$ cell (Treg) development. Cell Physiol Biochem. (2016) 39:985-95. doi: 10.1159/000447806

90. World Health Organization. Depression and Other Common Mental Disorders: Global Health Estimates. Licence: CC BY-NC-SA 3.0 IGO. (2017).

91. Wright NC, Looker AC, Saag KG, Curtis JR, Delzell ES, Randall S, et al. The recent prevalence of osteoporosis and low bone mass in the United States based on bone mineral density at the femoral neck or lumbar spine. J Bone Miner Res. (2014) 29:2520-6. doi: 10.1002/jbmr.2269

92. Roth AG, Drescher D, Yang Y, Redmer S, Uhlig S, Arenz C. Potent and selective inhibition of acid sphingomyelinase by bisphosphonates. Angew Chem Int Ed Engl. (2009) 48:7560-3. doi: 10.1002/anie.200903288

93. Arenz C. Small molecule inhibitors of acid sphingomyelinase. Cell Physiol Biochem. (2010) 26:1-8. doi: 10.1159/000315100

94. Pugliatti M, Rosati G, Carton H, Riise T, Drulovic J, Vecsei L, et al. The epidemiology of multiple sclerosis in Europe. Eur J Neurol. (2006) 13:700-22. doi: 10.1111/j.1468-1331.2006.01342.x

95. Mackenzie IS, Morant SV, Bloomfield GA, MacDonald TM, O'Riordan J. Incidence and prevalence of multiple sclerosis in the UK 1990-2010: a descriptive study in the General Practice Research Database. J Neurol Neurosurg Psychiatr. (2014) 85:76-84. doi: 10.1136/jnnp-2013-305450

96. Hose M, Gunther A, Abberger H, Begum S, Korencak M, Becker KA, et al. T cell-specific overexpression of acid sphingomyelinase results in elevated $\mathrm{T}$ cell activation and reduced parasitemia during Plasmodium yoelii infection. Front Immunol. (2019) 10:1225. doi: 10.3389/fimmu.2019.01225

Conflict of Interest: The authors declare that the research was conducted in the absence of any commercial or financial relationships that could be construed as a potential conflict of interest.

Copyright (c) 2019 Hollmann, Wiese, Dennstädt, Fink, Schneider-Schaulies and Beyersdorf. This is an open-access article distributed under the terms of the Creative Commons Attribution License (CC BY). The use, distribution or reproduction in other forums is permitted, provided the original author(s) and the copyright owner(s) are credited and that the original publication in this journal is cited, in accordance with accepted academic practice. No use, distribution or reproduction is permitted which does not comply with these terms. 